\title{
GESTÃO DOS PNEUS INSERVÍVEIS E SUA CONTRIBUIÇÃO PARA O PROGRAMA DE PREVENÇÃO À DENGUE, FEBRE CHIKUGUNYA E ZIKA VÍRUS NO MUNICÍPIO \\ DE CHAPECÓ (SC)
}

\author{
WASTE TIRES MANAGEMENT AND THEIR CONTRIBUTION TO THE DENGUE, \\ CHIKUGUNYA FEVER AND ZIKA VIRUS PREVENTION PROGRAM IN THE CHAPECÓ
}

(SC) MUNICIPALITY

\author{
Junir Antonio Lutinski ${ }^{1}$ \\ Suiane Oliveira de Quadros ${ }^{2}$ \\ Jéssica Tiburski ${ }^{3}$ \\ Cléia de Fátima Bedim ${ }^{4}$ \\ Recebido em: 19 jul. 2017 \\ Aceito em: 05 jun. 2018
}

RESUMO: O potencial dos pneus inservíveis como criadouros para o mosquito Aedes aegypti, vetor da Dengue, febre Chikungunya e Zika vírus, é amplamente conhecido. Este estudo teve como objetivos descrever a gestão dos pneus inservíveis no município de Chapecó e avaliar relação entre o número de pneus destinados à Reciclanip e o número de focos de $A$. aegypti registrados em pneus. A coleta de dados foi realizada no período de maio a agosto de 2016 e teve como base o período de 2010 a 2015. Dados foram obtidos no sitio eletrônico da DIVE/SC e junto ao setor de Vigilância em Saúde Ambiental do município de Chapecó. A quantidade de pneus inservíveis recebidos pelo ecoponto triplicou no período avaliado. A correlação entre a gestão ambientalmente correta dos pneus inservíveis e o número de focos de $A$. aegypti foi negativa $(r=-0,79)$ e significativa $(p<0,05)$. Os resultados encontrados permitem inferir que a gestão ambientalmente correta dos pneus inservíveis contribui positivamente para a promoção da saúde pública, na prevenção da Dengue, febre Chikungunya e Zika vírus.

Palavras-chave: Gestão de resíduos. Logística reserva. Promoção da saúde. Resíduos sólidos urbanos.

ABSTRACT: The potential of waste tires as breeding sites for the Aedes aegypti mosquito, Dengue, Chikungunya fever and Zika virus vector, is widely known. The aim of this study was to describe the management of waste tires in the municipality of Chapecó and to evaluate the relationship between the number of tires destined for Reciclanip and the number of $A$. aegypti outbreaks recorded in tires. Data collection was performed from May to August 2016 and was based on the period from 2010 to 2015. Data were obtained from the DIVE/SC website and from the Environmental

\footnotetext{
1 Programa de Pós-Graduação em Ciências da Saúde, Universidade Comunitária da Região de Chapecó (Unochapecó), Chapecó, SC, Brasil. E-mail: junir@unochapeco.edu.br

2 Curso de Ciências Biológicas, Universidade Comunitária da Região de Chapecó (Unochapecó), Chapecó, SC, Brasil. E-mail: jessica.tiburski@unochapeco.edu.br.

${ }^{3}$ Curso de Ciências Biológicas, Universidade Comunitária da Região de Chapecó (Unochapecó), Chapecó, SC, Brasil. E-mail: jessica.tiburski@unochapeco.edu.br.

4 Vigilância em Saúde Ambiental do município de Chapecó, SC, Brasil. E-mail: cleiabed@yahoo.com.br.
} 
Health Surveillance sector of Chapecó municipality. The amount of waste tires received by the ecopoint tripled in the evaluated period. The correlation between the environmentally correct management of the waste tires and the number of $A$. aegypti outbreaks was negative $(r=-0.79)$ and significant $(p<0.05)$. The results found allow to infer that the environmentally correct management of waste tires contributes positively to the promotion of public health in the prevention of Dengue, Chikungunya fever and Zika virus.

Keywords: Waste management. Reserve logistics. Health promotion. Urban solid waste.

\section{INTRODUÇÃO}

O desenvolvimento industrial do século XX aumentou a oferta de produtos destinados a satisfazer às necessidades da sociedade moderna resultando no aumento do consumo e em hábitos de descarte indiscriminados. Isso aumentou a pressão sobre os recursos naturais e ocasionou o esgotamento de recursos finitos. Houve um aumento na geração de resíduos perigosos e por consequência houve uma elevação da poluição do planeta (FERREIRA et al., 2011). A crise ambiental fez com que a sociedade passasse a se preocupar com o processo de crescimento econômico. A reflexão e discussão sobre as questões ambientais passou a fazer parte das agendas políticas e isso levou ao conceito de desenvolvimento sustentável, que surgiu na década de 80 , tendo-se em vista a relação entre a preservação ambiental do planeta e o atendimento das necessidades humanas (LEITE; ARAÚJO e MARTINS, 2011).

Segundo o relatório WCED (1987), o desenvolvimento sustentável deve ser capaz de satisfazer as necessidades da geração presente sem comprometer a capacidade das futuras gerações satisfazerem as suas próprias necessidades. O termo Desenvolvimento Sustentável representa um conceito integrador onde questões inter-relacionadas podem ser organizadas de forma única buscando a sustentabilidade. A sustentabilidade foi adotada inicialmente pelo movimento ecológico para atender e proteger aos recursos renováveis. Daí o conceito que se refere à existência de condições ecológicas para dar suporte à vida humana (SARTORI, LATRÔNICO e CAMPOS, 2014; FLORIANI et al., 2016).

Pneus inservíveis representam um resíduo que demanda de uma gestão ambientalmente correta. Quando disposto inadequadamente pode causar danos ao meio ambiente e à saúde pública (LAGARINHOS e TENÓRIO, 2013; FREITAS e NÓBREGA, 2014). A indústria brasileira de pneus produz um total de mais de 68 milhões de unidades ao ano (IBGE, 2015). Desse total, aproximadamente $87 \%$ são produzidas pelas oito empresas que representam a Associação Nacional da Indústria de Pneumáticos (ANIP). Dentre as alternativas para a destinação dos pneus inservíveis estão a recauchutagem, regeneração, reciclagem energética, pirólise e a composição asfáltica (SANDRONI e PACHECO, 2005).

A definição de pneus inservíveis veio com a Resolução Conselho Nacional do Meio Ambiente (CONAMA) nำ 258/99 que descreve pneus ou pneumáticos como todos os 
artefatos infláveis constituídos basicamente por borracha e materiais de reforço, utilizados para rodagem de veículos. Este resíduo não é classificado como perigoso (ABNT, 2004), contudo, em caso de incêndios, a fumaça resultante contém poluentes nocivos à saúde humana, podendo afetar o bem-estar físico e psicológico dos seres humanos (CHEN et al., 2009; NÓBREGA, 2014).

A reciclagem de pneus no Brasil teve avanços a partir da publicação da Resolução do CONAMA n 258/99 (BRASIL, 1999) e com o desenvolvimento de tecnologias para reutilização, reciclagem e valorização energética (LAGARINHOS e TENÓRIO, 2013). Em 2009, foi publicada uma nova Resolução CONAMA, a de no 416/09 (BRASIL, 2009a), que atualizou a forma de cálculo para a reciclagem de pneus produzidos para venda no mercado de reposição. Esta Resolução estabelece responsabilidades compartilhadas que envolvem a produção, comércio e os usuários dos pneus inservíveis. Indústrias, importadores, comércios, revendedores, a população e o poder público passaram a ter responsabilidades definidas no processo de gestão dos pneus inservíveis (BRASIL, 2009a; LAGARINHOS e TENÓRIO, 2013).

Embora o pneu seja um material considerado inerte, possui metais pesados em sua composição e sua disposição requer gerenciamento adequado (ARAUJO e SILVA, 2005). A partir das agressões ao meio ambiente, os países passaram a regulamentar e a adotar imposições mais rígidas aos diversos agentes envolvidos, sejam consumidores, empresas, poder público ou outras instituições (MOTTA, 2008).

Para atender à resolução CONAMA 416/2009, as indústrias pneumáticas se uniram e criaram a Associação Nacional da Indústria Pneumática (ANIP), a fim de sistematizar a coleta e a destinação final adequada dos pneus inservíveis produzidos no Brasil. Foram implantados em todo o país locais para coleta dos pneus chamados ecopontos, destinados a receber os pneus inservíveis, possibilitando a destinação ambientalmente correta desse resíduo e visando disseminar entre a população a existência de pontos para disposição dos pneus substituídos (RECICLANIP, 2016).

A logística reversa representa a área da logística empresarial que planeja, opera e controla o fluxo e as informações logísticas correspondentes, do retorno dos bens de pósvenda e de pós-consumo ao ciclo de negócios ou ao ciclo produtivo, através dos canais de distribuição reversos, atendendo à legislação vigente e agregando-Ihes valores de diversas naturezas. Uma das dificuldades enfrentadas na logística reversa dos pneus inservíveis se refere à falta de informações sobre a quantidade gerada e sobre os volumes gerados em cada região do Brasil (LAGARINHOS e TENÓRIO, 2008).

No Estado de Santa Catarina, o primeiro município a estabelecer convênio com a ANIP e um ecoponto com esta finalidade foi São Miguel do Oeste no ano de 2008, seguido pelo município de Chapecó, em 2009. Atualmente, estão cadastrados 19 ecopontos no Estado de Santa Catarina (RECICLANIP, 2016). Apesar de a legislação ambiental vigente tratar os pneus inservíveis como uma demanda primariamente ambiental, o processo de gestão destes resíduos vem ocorrendo intimamente associado à demanda criada para a prevenção dos riscos à saúde. Os programas municipais de prevenção à Dengue, Febre 
Chikungunya e Zika vírus, em parceria com a Diretoria de Vigilância Epidemiológica do Estado, têm estado na vanguarda da gestão dos pneus inservíveis no Estado catarinense. As três doenças são transmitidas pelo mosquito Aedes aegypti (Linnaeus, 1762), que encontra nos pneus a céu aberto um criadouro preferencial (BRASIL, 2009b).

No Brasil, as epidemias de dengue, tem ultrapassado a capacidade de atendimento nos serviços do Sistema Único de Saúde (TEIXEIRA, 2015). As infecções produzidas pelo vírus enfocam uma situação epidemiológica preocupante em vários países (MENDONÇA et al., 2009; WHO, 2012). A transmissão do agente etiológico tem sido registrada de uma forma de cada vez mais intensa, aumentando a magnitude das epidemias e a área de circulação do vírus (TEIXEIRA, 2015; VALLE, 2015). No Estado de Santa Catarina, nos dez primeiros meses do ano de 2016, foram notificados mais de 13 mil casos suspeitos da doença com confirmação de mais de $30 \%$ destes. O município de Chapecó está entre aqueles que lideram 0 ranking estadual dos casos confirmados da doença (SANTA CATARINA, 2016).

A febre causada pelo vírus Chikungunya (CHIKV) é uma doença emergente que vem se espalhando rapidamente e tem se tornado uma preocupação mundial. Inicialmente por não apresentar tratamento específico e vacina e, posteriormente, pelo seu alto poder de limitação (FRANCISCO e SALVADOR, 2013). Foram notificados 35 casos confirmados de febre Chikungunya no Estado de Santa Catarina, em 2016 (SANTA CATARINA, 2016). O Zika vírus é um arbovírus do gênero Flavivírus, pertencente à família Flaviviridae (OEHLER et al., 2014). Trata-se de uma infecção viral cujos sintomas podem incluir a microcefalia em recém-nascidos. Foram confirmados 25 casos no Estado em 2016 (SANTA CATARINA, 2016).

No município de Chapecó, o ecoponto atende 230 empresas e pelo menos 10 prefeituras da região. O local é gerido pelo setor de Vigilância em Saúde Ambiental e recebe, armazena e destina os pneus à Reciclanip. Os geradores (comércios de pneus, borracharias e empresas do setor de transportes) entregam os pneus sem custo no ecoponto e a Reciclanip faz a retirada sistemática sem ônus ou repasse de qualquer forma para o município (CHAPECÓ, 2016).

Diante deste contexto, este estudo aborda o seguinte problema de investigação: a gestão ambientalmente correta dos pneus inservíveis contribui para o controle populacional do mosquito $A$. aegypti? Este estudo objetivou a) descrever a gestão dos pneus inservíveis no município de Chapecó, no período entre 2010 e 2015, quanto aos volumes destinados à reciclagem e a sazonalidade; b) Avaliar a evolução do número de focos de $A$. aegypti registrados em pneus no mesmo período; e c) avaliar relação entre o número de pneus inservíveis destinados à Reciclanip e o número de focos de $A$. aegypti registrados em pneus. 


\section{MATERIAL E MÉTODOS}

\section{LOCAL DO ESTUDO}

Esta pesquisa se caracteriza como quantitativa e teve como fonte de dados a Diretoria de Vigilância Epidemiológica de Santa Catarina (Santa Catarina, 2016) e o banco de dados do setor de Vigilância em Saúde Ambiental do município de Chapecó (CHAPECÓ, 2016). Baseia-se nos dados relativos ao período entre 2010 e 2015. O município de Chapecó está localizado na região Oeste do Estado de Santa Catarina $\left(27^{\circ} 05^{\prime} 47^{\prime \prime}\right.$ S; 52037'06" W). Possui uma população estimada em 205.789 habitantes (IBGE, 2015). Destaca-se das demais cidades do oeste catarinense por ser considerado polo econômico regional e por se encontrar na rota do comércio e do turismo da região Sul do Brasil (CHAPECÓ, 2016). A infestação pelo mosquito A. aegypti em Chapecó conta com um histórico de duas décadas (LUTINSKI et al., 2013).

\section{COLETA DE DADOS}

A coleta de dados foi realizada no período de maio a agosto de 2016. Dados da Diretoria de Vigilância Epidemiológica de Santa Catarina (DIVE) foram obtidos no sitio eletrônico da DIVE e se restringiram aos dados secundários de natureza pública, disponíveis na página web. Foram obtidos dados referentes ao número de focos de $A$. aegypti registrados em pneus em todos os municípios catarinenses, ano a ano, para o período avaliado.

Dados relativos ao número de focos de $A$. aegypti registrados em pneus no município de Chapecó, mês a mês, em cada ano do período avaliado, ao número mensal de pneus recebidos pelo ecoponto de Chapecó, e a quantidade, em toneladas, destinada à Reciclanip, ano a ano, foram obtidos junto ao setor de Vigilância em Saúde Ambiental do município. Para tal, foram obtidas ciência e autorização da gestão municipal para o uso dos dados.

\section{ANÁLISE DOS DADOS}

Os dados foram tabulados e organizados em uma planilha de dados utilizando-se - Software Excel for Windows. Foi realizada uma análise estatística exploratória baseada nas frequências, ilustrada por tabelas e gráficos e mantidos aqueles que melhor responderam aos objetivos propostos.

Para avaliar a relação entre o número de pneus inservíveis destinados à Reciclanip e o número de focos de $A$. aegypti registrados em pneus, foi realizada uma análise de 
correlação de Pearson. Para tal, foi utilizado o Software estatístico Past (HAMMER et al., 2001).

\section{RESULTADOS}

Ao todo, 446.613 pneus foram recebidos pelo ecoponto de Chapecó, no período entre 2010 e 2015. Este total representou uma quantidade de 3.449,34 toneladas destinadas à Reciclanip. A quantidade de pneus recebidos no ecoponto aumentou aproximadamente três vezes no período (Tabela 1).

Tabela 1 - Número anual de pneus inservíveis recebidos no ecoponto do município de Chapecó e quantidade, em toneladas, destinada à Reciclanip, no período entre 2010 e 2015.

\begin{tabular}{lll} 
Ano & Quantidade de pneus destinados à Reciclanip (unidades) & Volume destinado à Reciclanip (toneladas) \\
\hline 201 & & \\
0 & 32.352 & 386,06 \\
201 & & \\
1 & 36.020 & 470,73 \\
201 & & \\
2 & 55.465 & 486,66 \\
201 & & 573,24 \\
3 & 51.815 & \\
201 & & 841,27 \\
4 & 161.327 & \\
201 & & 691,38 \\
5 & 109.634 &
\end{tabular}

As maiores quantidades de pneus recebidas no ecoponto foram verificadas nos meses de janeiro, fevereiro, junho, julho e agosto. As médias mensais destes meses diferiram significativamente (Erro Padrão) dos demais meses do ano (Figura 1). 


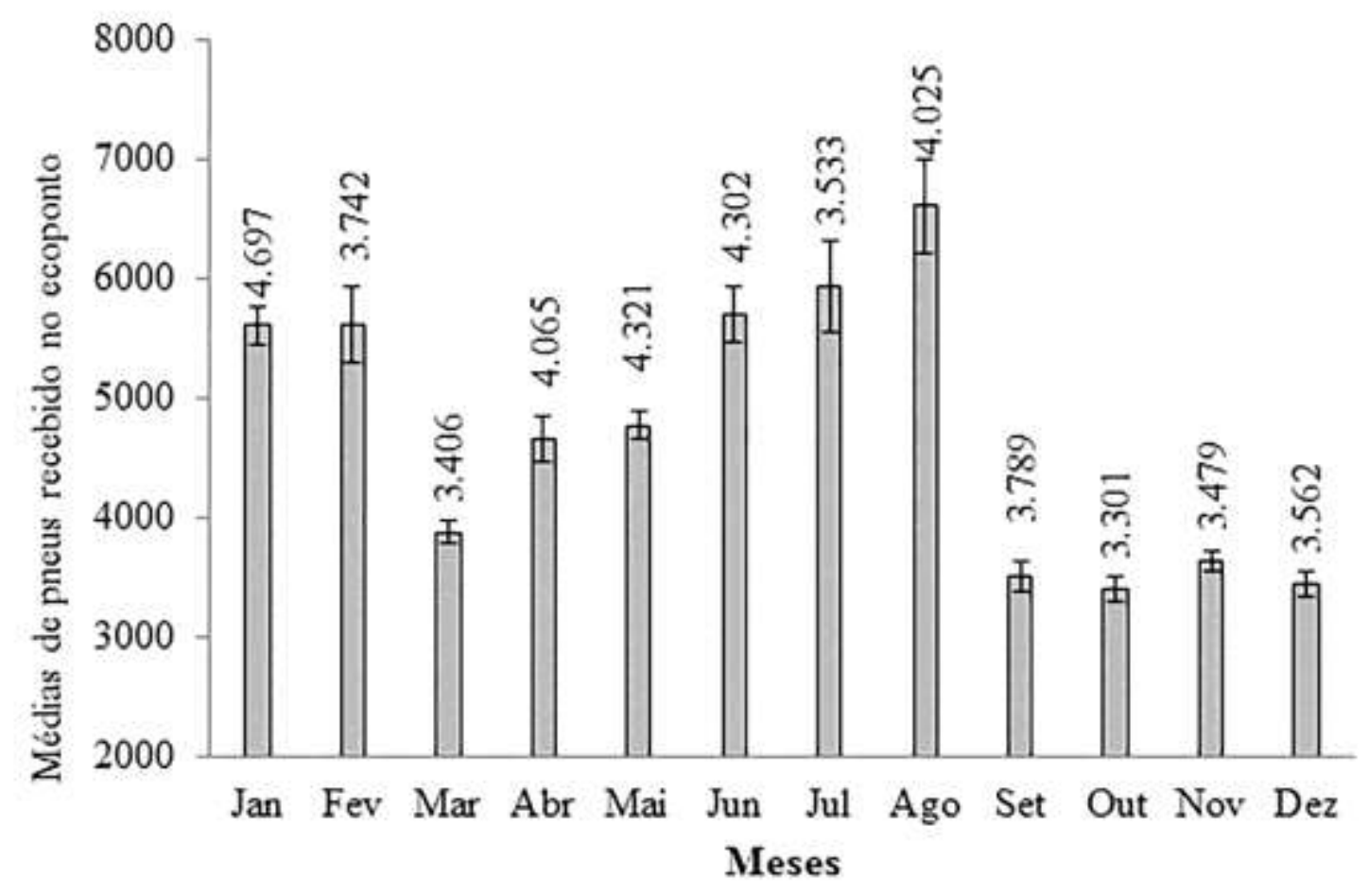

Figura 1 - Número médio mensal de pneus inservíveis recebidos pelo ecoponto de Chapecó. Período de 2010 a 2015. As barras verticais representam o Erro Padrão da média.

Os percentuais de focos de $A$. aegypti encontrados em pneus em relação ao total de focos registrados foi, em todos os anos, menor no município de Chapecó, do que os percentuais verificados para o Estado como um todo. Os percentuais verificados no município acompanharam a tendência observada no Estado. Entre 2010 e 2012, observouse uma redução de mais de $55 \%$ do índice, tanto no município como no Estado. A diferença (redução) ente os percentuais de 2010 e de 2015, em pontos percentuais foi de 4,9 para Chapecó e 5,4 para o Estado. Houve uma estabilização entre 2012 e 2014 e um leve aumento em 2015 (Figura 2). 


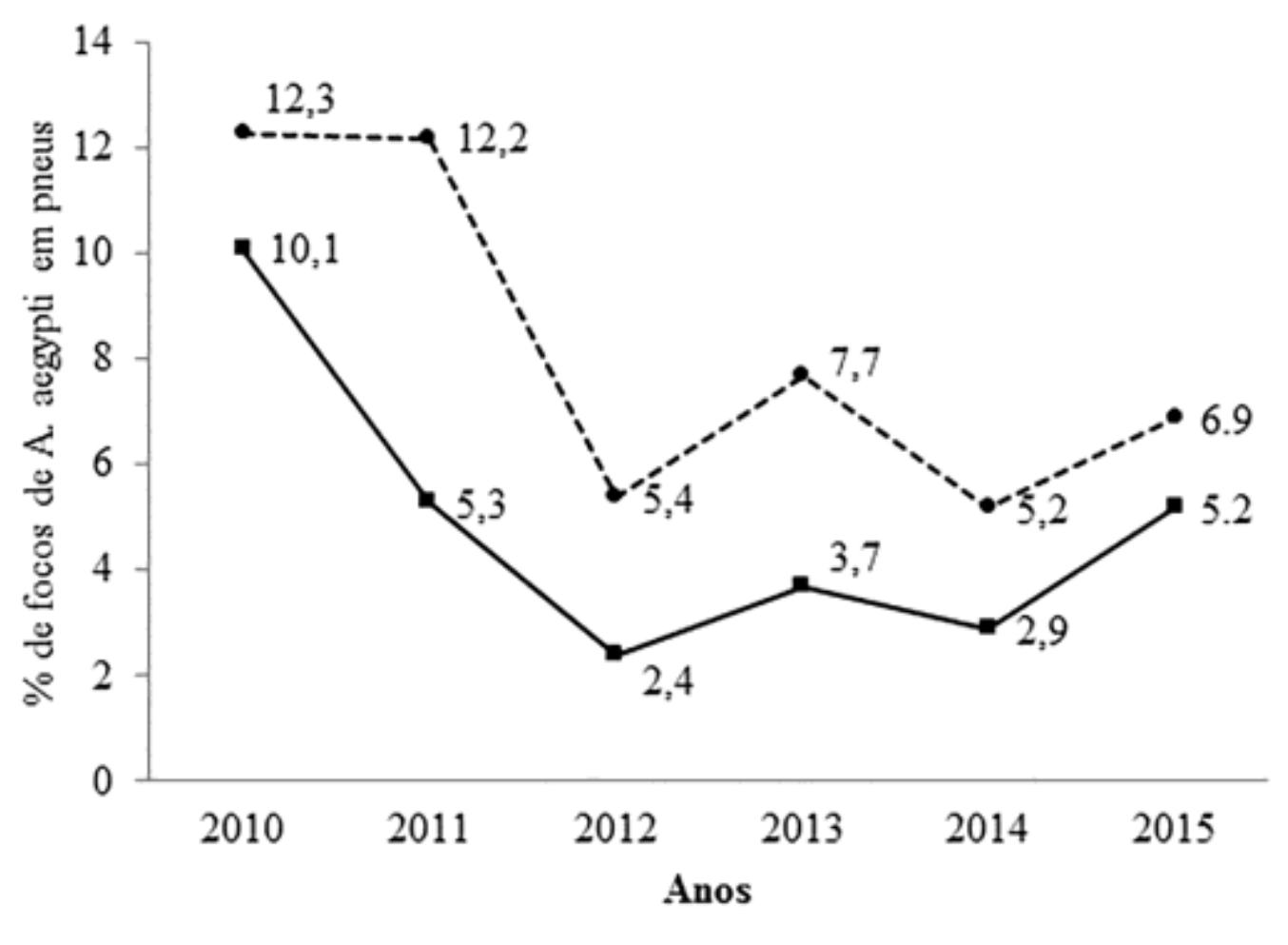

$\rightarrow$ Chapecó $\quad--\bullet--$ Santa Catarina

Figura 2 - Evolução anual dos percentuais de focos de $A$. aegypti encontrados em pneus inservíveis no município de Chapecó e no Estado de Santa Catarina, no período de 2010 a 2014.

Foi encontrada uma correlação negativa e significativa entre o percentual anual de focos de $A$. aegypti encontrados em pneus e o número de pneus destinados à Reciclanip (Figura 3). 


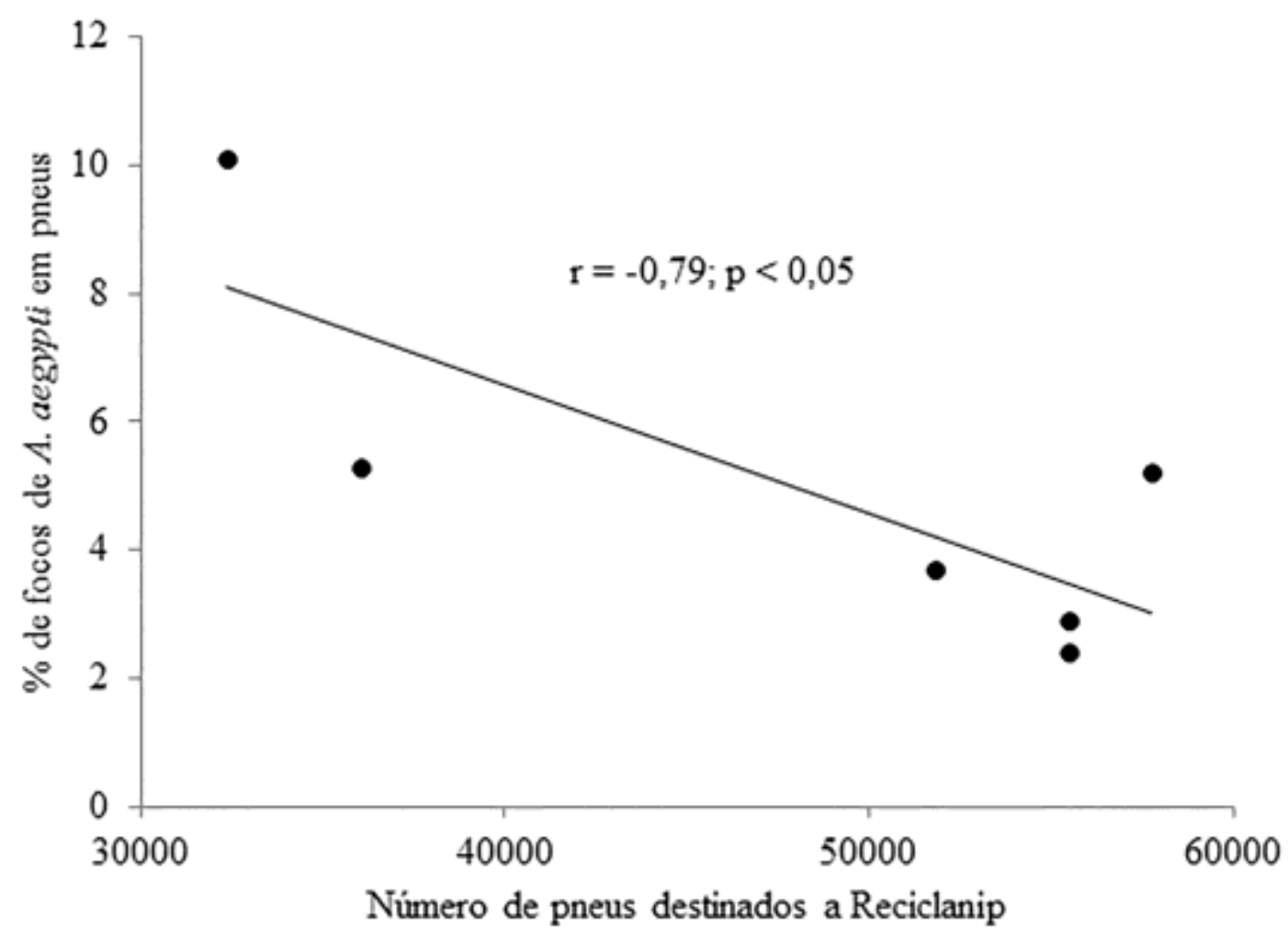

Figura 3 - Correlação entre o percentual de focos de $A$. aegypti registrados em pneus e o número de pneus destinados à Reciclanip, município de Chapecó, SC, no período de 2010 a 2015.

\section{DISCUSSÃO}

A quantidade de pneus recebidos pelo ecoponto de Chapecó e destinados à Reciclanip triplicou no período entre 2010 e 2016. Parte do período de maior número de pneus entregues no ecoponto, meses de janeiro e fevereiro, coincide com o período de intensificação das ações do Programa Municipal de Prevenção à Dengue (PMCD). Os meses de junho, julho e agosto representam o período imediatamente após o término das campanhas mais intensas de prevenção da Dengue, Febre Chukungunya e Zika vírus no município. Houve uma redução importante dos percentuais de focos encontrados em pneus inservíveis em relação ao total de focos registrados, tanto pelo município de Chapecó, como no Estado de Santa Catarina. A redução coincide com o período do estabelecimento dos termos de convênio dos municípios com a Reciclanip e a implantação dos ecopontos. A associação entre a gestão ambientalmente correta dos pneus inservíveis e a redução dos focos de $A$. aegypti foi significativa no período avaliado.

O aumento do número de pneus inservíveis recebidos no ecoponto de Chapecó reflete a produção e comercialização de pneus no Brasil. No ano de 2014, o país produziu 68 milhões de pneus e a comercialização que alcançou a marca de 75 milhões de unidades (RECICLANIP, 2016). Ao fim da vida útil, os pneus são descartados no momento em que são trocados por novos (LAGARINHOS e TENÓRIO, 2013). Até o ano de 2008, no município de Chapecó não contava com nenhuma destinação sistemática e regular de pneus inservíveis. Grandes empresas geradoras mantinham contatos independentes com 
empresas de destinação em outros Estados e assim faziam o descarte dos pneus inservíveis. Contudo, empresas de menor porte recorriam à doação a obras de contenção, muros ou ao descarte irregular em terrenos baldios. Esta destinação contribuiu para que, no município de Chapecó e no Estado de Santa Catarina, os pneus inservíveis tivessem um papel preponderante na infestação por $A$. aegypti e, posteriormente para a transmissão viral das doenças veiculadas por este mosquito (CHAPECÓ, 2016; SANTA CATARINA, 2016).

De acordo com Rodrigues e Henkes (2015), a reutilização de pneus inservíveis ganhou espaço após a segunda metade do século XX quando, segundo Rodrigues e Henkes (2015), à escassez de matéria-prima para a produção de pneus novos se tornou uma realidade. A reciclagem de pneus não gera, necessariamente, lucro para os fabricantes (ROY et al., 2006; FLORIANI et al., 2016). Contudo, o despertar de uma maior preocupação com a sustentabilidade do planeta, associada ao volume de pneus inservíveis gerados levou o governo a regulamentar o descarte deste resíduo (BRASIL, 2009a). Contudo, foi a partir do reconhecimento deste resíduo como uma ameaça à saúde pública que a logística reversa dos pneus inservíveis tomou impulso no município de Chapecó. Após a implantação do ecoponto, a divulgação, as campanhas de limpeza urbana para evitar a proliferação do mosquito $A$. aegypti, aliado à fiscalização sanitária nos estabelecimentos geradores contribuíram para o aumento do número de pneus recebidos no ecoponto, ano após ano.

O Ecossistema urbano está relacionado aos aspectos visíveis, externos do ambiente (monumentos, praças, ruas, imóveis e terrenos baldios) individualizados como elementos, porém componente intrínseco das relações que representam e explicam a paisagem. Trata-se de um ambiente em constante transformação, tanto no tempo, como e no espaço (LAMAS, 2000). A forma como uma cidade organizada influi em seu sistema de tráfego, na implantação dos equipamentos urbanos, nos custos de urbanização, além de exercer influência na vida socioeconômica do grupo social (FERRARI, 1991). A adoção de políticas adequadas de gestão dos resíduos representa uma necessidade atual, frente à expansão das inúmeras doenças transmissíveis emergentes e re-emergentes (RODRIGUES et al., 2016).

Os pneus inservíveis são resíduos sólidos que ocupam espaço muito físico, são de difícil compactação e demandam coleta e eliminação ambientalmente adequadas. $\mathrm{O}$ pneu não é um produto biodegradável e seu tempo de decomposição é estimado em séculos. Devido à sua composição química, que inclui metais pesados, borracha natural e sintética, negro de fumo e óleos, o pneu é produto de fácil combustão e tem alto poder calorífico, o que ocasiona, no caso da queima, a liberação de substâncias tóxicas e cancerígenas, poluentes orgânicos e inorgânicos, tais como fumos metálicos, hidrocarbonetos aromáticos policíclicos benzo(a)pireno e dioxinas (FGV, 2016; POMPEU, 2016).

Segundo Morosini (2006), os pneus inservíveis, quando descartados em cursos d'água, obstruem canais, córregos e galerias de águas pluviais, prejudicando a vazão de escoamento desses corpos receptores hídricos e contribuindo para as enchentes, onerando a administração pública e a população com perdas materiais e riscos à saúde. A queima de 
pneus a céu aberto é proibida em muitos países devido à emissão de substâncias potencialmente tóxicas. A destinação de pneus para aterros de resíduos é igualmente proibida (BRASIL, 2009) em função do risco de incêndios e da contaminação do solo e da água (FGV, 2016).

Pneus estocados também são locais ideais para a proliferação de mosquitos transmissores de doenças com elevado impacto social como a febre amarela, dengue, febre chikungunya e zika vírus (LUTINSKI et al., 2013). Pneus proporcionam o habitat ideal para a reprodução do mosquito $A$. aegypti devido a seu formato e, sobretudo, por estarem onipresentes tanto em ambientes urbanos quanto rurais. A introdução de novos vírus patogênicos reforça a demanda pela destinação correta destes resíduos. Além de servirem como criadouros, a importação de pneus contendo ovos de mosquitos representa um revés na luta contra a dengue no Brasil. Além de aumento nos custos destinados à prevenção, aumenta a necessidade de desenvolvimento de novos medicamentes e de novas produtos para a fumigação, aumentando ainda mais os impactos sobre o ambiente e sobre a saúde humana (LOPES, 1997; CLARO; TOMASSINI e ROSA, 2004; FGV, 2016).

A ação coordenada pela gestão pública municipal para a prevenção da Dengue está relacionada à sazonalidade da entrega dos pneus inservíveis no ecoponto (CHAPECÓ, 2016). As maiores médias do número de pneus inservíveis entregues no ecoponto nos meses de janeiro e fevereiro estão associadas ao maior número de trocas de pneus pela população no período que precede as viagens de férias. Já, as parcerias com prefeituras da região que reúnem estoques de pneus inservíveis durante os meses de fevereiro a maio em resposta aos riscos à saúde e posteriormente destinam os pneus para o ecoponto de Chapecó, explicam as maiores médias nos meses de junho, julho e agosto.

A demanda pela produção de pneus no mundo continua aumentando e com ela a necessidade de uma gestão eficiente dos pneus inservíveis após a vida útil deste produto (RODRIGUES e HENKS, 2015). A redução dos percentuais de focos de $A$. aegypti encontrados em pneus inservíveis, tanto em Chapecó, como no Estado de Santa Catarina como um todo, imediatamente após o estabelecimento dos convênios e da implantação dos ecopontos, representa um indicativo da contribuição de uma gestão eficiente destes resíduos para a promoção da saúde e para a prevenção de doenças como a Dengue, Febre Chukungunya e Zika vírus.

O mosquito $A$. aegypti apresenta um longo histórico de convivência com o ser humano e atualmente é considerado uma espécie sinantrópica. Utiliza como criadouros os mais variados recipientes que possam acumular água parada nos ambientes intra ou peridomiciliares (TAUIL, 2002). Os mais comuns são pneus inservíveis, latas, garrafas, pratos dos vasos de plantas, caixas d'água descobertas, calhas, piscinas e vasos sanitários sem uso (SANTA CATARINA, 2016). A pesquisa realizada por Souza-Santos (1999) confirma a maior produtividade de $A$. aegypti em pneus, dentre todos os outros recipientes propícios para a disposição de ovos. Pneus conseguem armazenar grande quantidade de água, por longos períodos e por isso proporcionam baixa perda de formas imaturas do mosquito (REITER et al., 1991). Daí a importância dos resultados deste estudo ao 
evidenciar a redução dos focos a partir da implantação do ecoponto.

A Dengue, febre Chukungunya e Zika vírus se tornaram um problema de saúde pública sendo responsável por causar epidemias anualmente em todas as regiões brasileiras, onde condições sociais, climáticas, ecológicas e ambientais favorecem a proliferação do vetor contribuindo com a circulação viral (SOUZA e LEITE, 2010; LUTINSKI et al., 2013). A despeito do potencial de poluição ambiental que os pneus inservíveis inadequadamente destinados representam (HORNER, 1996), a gestão deste resíduo se torna cada vez mais um imperativo para a promoção da saúde.

\section{CONSIDERAÇÕES FINAIS}

Dada a complexidade de fatores envolvidos no controle populacional do mosquito A. aegypti e na prevenção da Dengue, febre Chukungunya e Zika vírus (TAUIL, 2002), não tem sido simples o estabelecimento de relação entre causa e efeito de quaisquer das inúmeras técnicas e soluções propostas. É evidente que a gestão dos pneus inservíveis sem a implementação de ações concomitantes de saneamento básico como um todo surtirá pouco efeito efetivo no controle da população do inseto vetor. Não havendo pneus inservíveis no ambiente, o inseto não terá dificuldades para encontrar outros criadouros em potencial. Por isso, este estudo não tem a pretensão de apresentar uma solução definitiva para um problema que assola as cidades brasileiras, e sim contribuir com um relato de uma experiência que vem apresentando resultados promissores.

Os resultados encontrados permitem inferir que a gestão ambientalmente correta dos pneus inservíveis contribui positivamente para a promoção da saúde pública, além atender à legislação ambiental vigente. Os relatos deste estudo poderão contribuir para o planejamento e para o estabelecimento de planos de gerenciamento de pneus inservíveis em outros municípios do pais. Também poderão subsidiar estratégias de controle vetorial integrando setores da Saúde, Planejamento, Limpeza urbana, Educação e Comunicação.

\section{REFERÊNCIAS}

ABNT. NBR 10004: Classificação dos resíduos sólidos. Rio de Janeiro: Associação Brasileira de Normas Técnicas, 2004.

ARAÚJO, F. C.; SILVA, R. J. da. Pneus inservíveis: análise das leis ambientais vigentes e processos de destinação final adequados. XXV Encontro Nacional de Engenharia de Produção, Porto Alegre, RS, Brasil, p. 1-8, 2005.

BRASIL, CONAMA - Conselho Nacional de Meio Ambiente. Resolução CONAMA no 258/99, de 20 de agosto de 1999. Resoluções, 1999a. Disponível em: http://www.mma.gov.br/port/conama. Acesso em: 7 nov. 2016.

BRASIL, CONAMA - Conselho Nacional de Meio Ambiente. Resolução CONAMA no 
416/09, de 30 de setembro de 2009. Resoluções, 2009a. Disponível em: Acesso em: http://www.mma.gov.br/port/conama. Acesso em: 7 nov. 2016.

BRASIL. Diretrizes nacionais para prevenção e controle de epidemias de dengue. Ministério da Saúde, Secretaria de Vigilância em Saúde, Departamento de Vigilância Epidemiológica. Brasília: Ministério da Saúde. 2009b.

CHAPECÓ. Prefeitura de Chapecó, Vigilância em Saúde Ambiental, 2015. Disponível em: https://www.chapeco.sc.gov.br/. Acesso em: 30 jun. 2016.

CHEN, C. C.; YAMADA, T.; CHIU, M., LIU, Y. Evaluation of the waste tire resources recovery program and environmental health policy in Taiwan. International Journal of Environmental Research and Public Health, v. 6, n. 3, p. 1075-1094, 2009.

CLARO, L. B. L.; TOMASSINI, H. C. B.; ROSA, M. L. G. Prevenção e controle do dengue: uma revisão de estudos sobre conhecimentos, crenças e práticas da população.

Cadernos de Saúde Pública, v. 20, n. 6, p. 1447-1457, 2004.

FERRARI, C. Curso de planejamento municipal integrado (7a. ed.). São Paulo: Pioneira, 1991.

FERREIRA, J. H. M.; CUNHA, L. T.; ALBUQUERQUE JÚNIOR E. P.; BARROS NETO, J. P. Sistema de Gestão Ambiental ISO 14001 e o Nível de Tratamento de Resíduos sob o enfoque da Produção Verde. In: Encontro de Estudos em Estratégia, 5., Porto Alegre. Anais... Porto Alegre: ANPAD, 2011.

FGV. Dossiê sobre pneus. Fundação Getúlio Vargas, 2016. Disponível em:

http://direitosp.fgv.br/sites/direitogv.fgv.br/files/ap18.pdf. Acesso em: 23 de dez. 2016.

FLORIANI, M. A.; FURLANETTO, V. C.; SEHNEM, S. Descarte sustentável de pneus inservíveis. Navus, v. 6, n. 2, p. 37-51, 2016.

FRANCISCO, G. L.; SALVADOR, F. S. Febre Chikungunya. In 13 Congresso Nacional de Iniciação Científica, Anais do Conic-Semesp. Campinas: Faculdade Anhanguera de Campinas, 2013.

FREITAS, S. S.; NÓBREGA, C. C. Os benefícios do coprocessamento de pneus inservíveis para a indústria cimenteira. Engenharia Sanitária e Ambiental, v. 19, n. 3, p. 293-300, 2014.

HAMMER, O.; HARPER, D. A. T.; RIAN, P. D. Past: Palaeonthological statistics software package for education and data analysis. Versão1.37. 2001. Disponível em: http://palaeo-electronica.org/2001_1/past/issue1_01.htm. Acesso em: 23 mar. 2016.

HORNER, J. M. Environmental health implications of heavy metal pollution from car tires. Journal of Environmental Health, v. 11, p. 175-178, 1996.

IBGE. Instituto Brasileiro de Geografia e Estatística. Cidades, 2015. Disponível em: http://www.ibge.gov.br/cidadesat/default. Acesso em: 10 ago. 2016.

LAGARINHOS, C. A. F.; TENÓRIO, J. A. S. Tecnologias Utilizadas para a Reutilização, Reciclagem e Valorização Energética de Pneus no Brasil. Polímeros: Ciência e Tecnologia, v. 18, n. 2, p. 106-118, 2008. 
LAGARINHOS, C. A. F.; TENÓRIO, J. A. S. Logística reversa dos pneus usados no Brasil. Polímeros, v. 23, n. 1, p. 49-58, 2013.

LAMAS, J. M. R. G. Morfologia urbana e desenho da cidade (2a ed.). Lisboa: Fundação Calouste Gulbenkian, 2000.

LEITE, L.; ARAÚJO, J. B.; MARTINS, R. A. Sustentabilidade como direcionador de evolução dos sistemas de medição de desempenho. Navus - Revista de Gestão e Tecnologia, v. 1, n. 1, p. 35-50, 2011.

LEITE, P. R. Logística reversa, meio ambiente e competitividade. São Paulo: Prentice Hall, 2003.

LOPES, J. Ecologia de mosquitos (Diptera: Culicidae) em criadouros naturais e artificiais de área rural do Norte do Estado do Paraná, Brasil. Coleta de larvas em recipientes artificiais instalados em mata ciliar. Revista de Saúde Pública, v. 31, n. 4, p. 370-377, 1997.

LUTINSKI, J. A.; ZANCHET, B.; GUARDA, C.; CONSTANCI, C.; FRIEDRICH, D. V.; CECHIN, F. T. C.; BONES, I. A.; SOUZA, M. F.; BALSAN, S. T.; ZARYCHTA, S. M.; BUSATO, M. A. Infestação pelo mosquito Aedes aegypti (Diptera: Culicidae) na cidade de Chapecó-SC. Biotemas, v. 26, n. 2, p. 143-151, 2013.

MENDONÇA, F. A.; SOUZA, A. V.; DUTRA, D. A. Saúde pública, urbanização e dengue no Brasil. Sociedade \& natureza, v. 21, n. 3, p. 257-269, 2009.

MOROSINI, F. A Guerra dos Pneus. Casoteca Latino-americana de Direito e Política Pública, p. 1-34, 2006.

MOTTA, F. G. A cadeia de destinação dos pneus inservíveis: o papel da regulação e do desenvolvimento tecnológico. Revista Ambiente e Sociedade, v. 11, n. 1, p. 167-184, 2008.

NÓBREGA, C. C.; FREITAS, S. S. Os benefícios do coprocessamento de pneus inservíveis para a indústria cimenteira: The benefits of co-processing wasted tires for the cement industry. Engenharia Sanitária e Ambiental, v. 19, n. 3, p. 293-300, 2014.

OEHLER, E.; WATRIN, L.; LARRE, P.; LASTÈRE, S.; VALOUR, F.; BAUDOUIN, L. Zika virus infection complicated by Guillain-Barré syndrome - case report, French Polynesia.

Euro Surveilliance, v. 19, n. 9, p. 7-9, 2014.

POMPEU, A. M. Logística reversa de pneus inservíveis: alternativa para o desenvolvimento local sustentável. Campo Grande: Universidade Católica Dom Bosco, 68 p. Dissertação (mestrado em desenvolvimento local), 2016.

RECICLANIP. Associação nacional da indústria de pneumáticos (ANIP). Ecopontos, 2016. Disponível em: http://www.anip.com.br. Acesso em: 23 ago. 2016.

REITER, P.; AMADOR, M. A.; COLON, N. Enhancement of the CDC ovitrap with hay infusion for daily monitoring of Ae. aegypti populations. Journal of the American Mosquitoes Control Association, v. 7, p. 52-5, 1991.

RODRIGUES, C. M.; HENKES, J. A. Reciclagem de pneus: atitude ambiental aliada à 
estratégia econômica. Revista Gestão e Sustentabilidade Ambiental, v. 4, n. 1, p. 448473, 2015.

RODRIGUES, W.; MAGALHÃES FILHO, L. N. L.; PEREIRA, R. S. Análise dos determinantes dos custos de resíduos sólidos urbanos nas capitais estaduais brasileiras. Revista Brasileira de Gestão Urbana (Brazilian Journal of Urban Management), v. 8, n. 1, p. 130-141, 2016.

ROY, J.; NOLLET, J.; BEAULIEU, M. Reverse logistics networks and governance structures. Supply Chain Forum An International Journal, v. 7, n. 2, p. 58-67, 2006.

SANDRONI, M.; PACHECO, E. B. A. V. O destino dos pneus inservíveis. 2005. Disponível em: http://www.jorplast.com.br/jpout03/pag08. Acesso em: 29 mai. 2016.

SANTA CATARINA. Secretaria de Estado da Saúde. Diretoria de Vigilância Epidemiológica. 31ํ Boletim Epidemiológico/2016. Situação da dengue, febre do chikungunya e zika vírus em Santa Catarina. 2016. Disponível em:

http://www.dive.sc.gov.br/. Acesso em: 29 mai. 2016.

SARTORI, S.; LATRÔNICO, F.; CAMPOS, L. M. S. Sustentabilidade e desenvolvimento sustentável: uma taxonomia no campo da literatura. Ambiente \& Sociedade, v. 17, n. 1, p. 1-22, 2014.

SOUZA, A.; LEITE, J. C. J. A dengue no município de Santo Amaro: aplicação de geoprocessamento para diagnóstico e análise dos casos. In: Congresso de pesquisa e inovação da rede norte nordeste de educação tecnológica, 2010, Salvador. Resumos. Salvador: CONNEPI, 2010. CDROM. 2010.

SOUZA-SANTOS, R. Fatores associados à ocorrência de formas imaturas de Aedes aegypti na Ilha do Governador, Rio de Janeiro, Brasil. Revista da Sociedade Brasileira de Medicina Tropical, v. 32, p. 373-82, 1999.

TAUIL, P. L. Aspectos críticos do controle do dengue no Brasil. Cadernos de Saúde Pública, v. 18, n. 3, p. 867-871, 2002.

TEIXEIRA, M. G.; COSTA, M. C. N.; BARRETO, M. L.; BARRETO, F. L. Epidemiologia da Dengue. In: VALLE, D.; PIMENTA, D. N. (Orgs.). Dengue: teorias e práticas. Rio de Janeiro: Fiocruz, 2015.

VALLE, D.; PIMENTA, D. N.; CUNHA, R. V. da. Dengue: teorias e práticas. Rio de Janeiro: Fiocruz, 2015.

WCED. World commission on environment and development. Our common Future. Oxford: Oxford University Press, 1987.

WHO. World Health Organization. Global Strategy for Dengue Prevention and Control 2012-2020. Geneva: World Health Organization, 2012. 